\title{
Different Biomarkers Address Different Colorectal Cancer Stem Cell Populations: Who's the Killer?
}

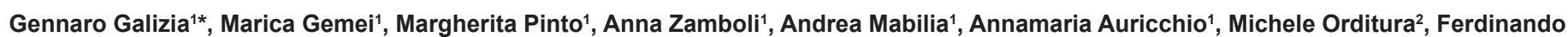
De Vita ${ }^{2}$, Eva Lieto ${ }^{2}$ and Ciro Romano ${ }^{3}$

${ }^{1}$ Division of Surgical Oncology, Department of Clinical and Experimental Medicine and Surgery, Second University of Naples School of Medicine, Naples, Italy ${ }^{2}$ Division of Medical Oncology, Department of Clinical and Experimental Medicine and Surgery, Second University of Naples School of Medicine, Naples, Italy ${ }^{3}$ Division of Internal Medicine, Allergy and Clinical Immunology, Department of Medicine, Second University of Naples School of Medicine, Naples, Italy

\begin{abstract}
Recent findings suggested the presence in several cancers, comprising colorectal malignancies, of a small subset of tumor-initiating cells, or cancer stem cells. So the isolation and characterization of tumorigenic colorectal cancer cells was extremely important for the development of new diagnostic and therapeutic procedures. Even if a defined and universally approved phenotype of colorectal cancer stem cells has not been defined yet, several markers have been reported able to isolate cancer stem-like cells. For the majority of these markers, it has not been associated a clear function but more of them seem to be involved in colon cancer stem cell maintenance, survival and proliferation through well known pathways such as the Wnt- $\beta$-catenin pathway whose activity has been demonstrated to define colorectal cancer stem cells. Even if the knowledge on colorectal cancer stem cell "functioning" is still little detailed and elusive, the importance to develop new therapeutic strategies that precisely target colorectal cancer stem cells prompted researchers to test different approaches to this aim. We summarize here the phenotypic and functional characteristics associated with colon cancer stem cells along with the approaches experimented to selectively target and kill these cancer cells. We also reviewed innovative approaches targeting colorectal cancer stem cells based on new delivery systems to precisely kill them or also on the combination of conventional therapies with functional dietary elements.
\end{abstract}

\section{Introduction}

Cancers arise from sequential mutations in oncogenes and or tumor suppressor genes. In the case of colorectal cancer, at least 45 different mutational events have been demonstrated to be necessary for the malignant evolution of a normal colonic cell [1]. Progression from normal colonic tissue to carcinoma through adenoma is characterized by accumulating abnormalities in specific genes. This transformation requires failure of tumor suppressor mechanisms involving such genes as adenomatous poliposis coli (APC), p53, transforming growth factor- $\beta$ (TGF- $\beta$ ), small mother against decapentaplegic (SMAD), and activation of oncogenic pathways, as those mediated by rat sarcoma (RAS), v-raf murine sarcoma viral oncogene homolog B1 (BRAF), and phosphoinoside 3-kinase (PI3K) [2]. Alterations in cell proliferation and apoptosis deriving from the perturbation of these pathways increase the risk of developing colorectal cancer.

For a long time, tumors have been looked as a mixture of equally tumorigenic cells arising from gene mutations in a so called stochastic model view [3,4]. When a restricted subset of cells was discovered in acute myeloid leukemia (AML), which retained the ability to recapitulate the original tumor upon serial transplantations, a new model was formulated. According to this view, tumors could be considered to have a hierarchic organization, with only more "immature" cancer stem cells capable to sustain cancer growth with time [5]. Soon after the discovery of a cancer stem cell subset acting as the root of tumor in hematological malignancies, several solid tumors, including colorectal malignancies, were demonstrated to be sustained by cancer stem cells as well [6-8]. Cancer stem cells are defined by stem cell-like features shared with the normal counterpart from which they seem to derive, through acquisition of genetic and epigenetic changes [9] and, in particular for colorectal cancer, there are evidences that colorectal cancer stem cells (CCSCs) arises from the transformation of normal stem cells which acquire a transformed phenotype [10]. In this article we reviewed the markers used for the identification and isolation of normal colon stem cells and then for colorectal cancer stem-like cells. This is because the vast majority of these markers are shared by the normal and the cancer stem-like populations. We then dealt with the function of the reviewed markers and finally we summarized the putative innovative therapeutic approaches to colorectal cancer treatment based on the specific targeting of colorectal cancer stem-like cells.

\section{Characterization and Markers of Normal Colon Stem Cells}

The inner luminal layer of the human colon consists of a single stratum of epithelial cells, folded into finger-like invaginations to form the functional unit called crypt of Lieberkuhn [11]. Stem cells reside inside the colonic crypt. Intestinal stem cells are involved in constant replacement of the intestinal epithelium under the influence of the surrounding microenvironment [12]. Each crypt is surrounded by stromal cells to form a niche, a complex structure of cellular and extracellular components promoting and sustaining stem cell maintenance and function. Epithelial-mesenchymal interactions are fundamental for the proper definition of the balance between proliferation and differentiation as well as for the regulation of the

*Corresponding author: Gennaro Galizia, Second University of Naples School of Medicine, Department of Clinical and Experimental Medicine and Surgery, II Policlinico, Edificio 17, 580131 Naples, Italy, Tel: +39-081-566-6613; Fax: +39-081566-6817; E-mail: gennaro.galizia@unina2.it

Received June 01, 2012; Accepted June 10, 2012; Published July 12, 2012

Citation: Galizia G, Gemei M, Pinto M, Zamboli A, Mabilia A, et al. (2012) Different Biomarkers Address Different Colorectal Cancer Stem Cell Populations: Who's the Killer? J Mol Biomarkers Diagn S8:004. doi:10.4172/2155-9929.S8-004

Copyright: @ 2012 Galizia G, et al. This is an open-access article distributed under the terms of the Creative Commons Attribution License, which permits unrestricted use, distribution, and reproduction in any medium, provided the original author and source are credited 
intestinal architecture through Wingless/Int (Wnt), hedgehog (HH), bone morphogenetic protein (BMP) and Notch signaling pathways [13-20].

Intestinal stem cell identification is a matter of controversy. No specific and widely accepted markers have been identified and a functional definition of these cells is based on their properties of selfrenewal and generation of a differentiated heterogeneous progeny. It appears that two pools of stem cells coexist in the intestinal crypt according to two different theories. One pool is supposed to be in the +4 position and is characterized by Bmi-1 and Tert expression [2123,12 ], while the pool located at the bottom (according to the stem cell zone theory) is characterized by expression of the Lgr-5 Wnt target gene [24,25]. Even though its function remains unclear, Lgr-5 is one of the best established markers for normal colonic stem cells [24]. Its expression at the base of the crypt, along with the ability of Lgr5+ cells to generate a whole crypt in vitro, made Lgr-5 a useful marker for colon stem cell identification [24]. In addition, other Wnt target gene products appear to be useful as colon stem cell markers. Specifically, the Ephrin receptors have been associated with both stemness maintenance and regulation of differentiation as well as with regulation of migration along the crypt walls [26,27]. Up to date, several other markers have been shown to be expressed in colon stem cells, such as Musashi-1 (Msi-1), CD29, aldheyde dehydrogenase-1 (ALDH-1), doublecortin and CaM-kinase-like-1 (DCAMKL-1), polycomb complex protein Bmi-1, and CD166. Msi-1 is a RNA-binding protein which appears to be fundamental for asymmetric distribution of molecules in the development of the nervous system and for maintaining an undifferentiated state of stem cells in mammals [28]. Nishimura et al. found this molecule to be also expressed in the lower part of the colonic crypts where stem cells reside [29]. CD29 has been reported to be a marker of the proliferative zone of colonic crypts, being shared by stem and progenitor cells [30]. DCAMKL-1 has also been proposed as a colon stem cell marker because its expression overlaps partially with that of Msi- 1 and is a feature of apoptosis resistant cells after radiation exposure [31]. Expression of Bmi-1, which is deemed essential for self-renewal of adult neural and hematopoietic stem cells, has also been found in the lower part of the crypt, although not properly at the bottom [11]. Recently, the activated leukocyte cell adhesion molecule CD166, which has previously been detected on colorectal cancer stem cells, has been proposed as a normal colon stem cell marker. CD166 expression has been observed at the base of the colonic crypts on cells co-expressing Msi-1, Lgr5, and DCAMKL-1 [32].

\section{Characterization and Markers of Colorectal Cancer Stem Cells}

Colorectal cancer stem cell characterization is still ongoing since no definitive information is available concerning the several molecules expressed by such cells (Table 1). [20,33-44,10] A conspicuous number of markers used for identification of CCSCs is shared by the normal counterpart from which they seem to derive [10] .

In colorectal cancer, a pentaspan trans-membrane glycoprotein, known as prominin-1 or CD133, has first been used for isolation of stem cell-like cancer cells $[7,8]$. CD133+ colon cancer cells proved to be highly tumorigenic in mouse and were endowed with the ability to recapitulate the original tumor [7,8]. Moreover, CD133+ colon cancer cells could be maintained in vitro as sphere cultures for years without loss of their clonogenic potential $[7,8]$. Under differentiation conditions, CD133+ colon cancer cells have been shown to be able to form crypt-like structures, with expression of differentiation markers [45]. In addition, CD133+ spheroids obtained from colon cancer cells derived by fresh colon cancer tissues were demonstrated to display the colon stem cell marker Msi-1 [45]. However, the role of CD133 as a cancer stem cell marker is controversial, due to the heterogeneous nature of the CD133+ colon cancer cell population, which is mainly composed by more differentiated progenitors (only 1 in 262 CD133+ colon cancer cells bears stem properties) [8]. Conversely, even CD133colon cancer cells have been shown to possess a tumorigenic capability in mouse models [46]. Accordingly, a number of colon cancers has been associated with undetectable levels of CD133, thus questioning the reliability of CD133 as a marker for CCSC identification [6]. Finally, silencing of CD133 in colon cancer has not been demonstrated to impair tumorigenicity of cancer cells, suggesting only a marginal role for CD133 as a colon stem cell marker and potential molecular target $[33,47]$.

Dalerba and colleagues investigated the role of two other markers, namely CD326 and CD44, to be used in combination to isolate CCSCs [6]. This approach allowed isolation of a tumorigenic CD44+ colon cancer cell population within the CD326+ epithelial tumor cell subset [6]. Although CD326 is often used for mere identification of epithelial cells in suspensions of digested colon cancer biopsies, a putative role in colon tumorigenesis has also been proposed $[34,48]$. Sorted CD44+ colon cancer cells have been used to faithfully reproduce parental tumors when injected into mice, and in vitro sphere cultures have been reported to retain clonogenic ability in time [6]. On the other hand, CD44 silencing has been shown to impair colon cancerogenesis

\begin{tabular}{|l|l|l|l|}
\hline Marker & Other name & Function & Role in colon tumorigenesis \\
\hline Lgr5 & - & Unknown & Prognostic factor, adenoma formation \\
\hline Wnt activity & - & Signalling pathway & $\begin{array}{l}\text { Normal colon-adenoma transition, stem phenotype mainte- } \\
\text { nance }\end{array}$ \\
\hline CD44 & [20] & Cell adhesion, hyaluronic acid receptor & $\begin{array}{l}\text { Colony formation, xenografts growth, prognostic factor, cor- } \\
\text { relation with tumor stage }\end{array}$ \\
\hline [33,35] & Tumor budding, metastatization \\
\hline CD326 & EpCAM & Cell adhesion & Association with tumor stage \\
\hline Msi-1 & - & RNA-binding protein & Resistance to alkylating agents, prognostic factor \\
\hline CD26 & - & Detoxifyng enzime & Metastatization \\
\hline Eph B2 & DPP4 & Cell surface glycoprotein & Cell compartimentalization \\
\hline CD166 & - & Wnt target gene & Prognostic factor \\
\hline CD133 & ALCAM & Cell adhesion & Prognostic factor \\
\hline CD29 & Prominin-1 & Cell motility and iron metabolism & Colony formation \\
\hline CD24 & Integrin $\beta 1$ subunit & Cell adhesion & $\begin{array}{l}\text { Clonogenic ability, multilineage potential, correlation with } \\
\text { invasiveness and survival }\end{array}$ \\
\hline
\end{tabular}

Table 1: Molecules expressed by colorectal cancer stem cells. 
$[35,37,49]$. Combined detection of CD166, CD44, and CD326 has been proposed to improve identification of CCSCs [6]. Recent studies have suggested the double positive CD133+/CD44+ colon cancer cells to represent a more purified subset of CCSCs [50-52]. We and others have indeed reported on a possible association between CD133+/CD44+ colon cancer cells and clinical outcome in colon cancer patients [53]. For other putative cancer stem cell markers, such as the $\beta 1$ integrin subunit CD29, the microtubule-associate kinase DCAMKL-1, and the detoxifying enzyme aldheyde dehydrogenase (ALDH-1), evidence is currently scant $[36,37]$.

Recently, phenotypically distinct populations within the same colorectal tumor have been shown to be responsible for different aspects of the tumorigenic process, that is, primary tumor growth, tumor recurrence, and metastatization [54]. In this regard, a stem celllike subpopulation of colorectal cancer cells responsible for metastasis formation has been identified by CD26 expression [38].

CCSCs have also been functionally associated with Wnt signaling pathway activation, due to both its pivotal role in colorectal cancerogenesis and the ability to revert differentiated cancer cells to a stem-like phenotype in a permissive microenvironment [20]. Interestingly, the colon cancer stem cell marker Lgr-5, which appears to be expressed by tumor-initiating cells, is a Wnt target gene [10,55]. Likewise, other Wnt target gene products, such as the Ephrin B (EphB) receptors, have been shown to be up-regulated in CCSCs. [39] EphB2 expressing colon cancer cells have been displayed to be endowed with both tumor-initiating capability in vivo and long-term self-renewal potential [39]. Finally, the PI3K/Akt pathway has also been shown to be involved in progenitor cell activation during colorectal carcinoma development, by activation of $\beta$-catenin signaling [56].

\section{Functions of CCSC Markers}

Function of colorectal cancer stem cell markers is generally unclear, as they are chosen as putative cancer stem cell identifiers because of shared expression in other malignancies or in normal stem cells. Although function is often uncertain, a correlation between expression of some of these markers as CD133, CD166, CD44s, EpCAM, ALDH-1 and patient prognosis has frequently been reported [40]. Besides, some of these markers appear to have a different function depending on cancer histotype. For instance, CD24 has been shown to be down-regulated in breast cancer stem cells [57], but up-regulated in pancreatic neoplasms [58].

With regard to colon cancer, CD24 has been shown to be expressed by colorectal cancer cells and to be involved in cell-cell interactions, cell adhesion, proliferation, and invasiveness $[41,42,59,60]$. CD24 expression is usually associated with detection of CD29, the $\beta 1$ integrin subunit, which is also involved in adhesion and, putatively, in migration and metastatization [42]. Likewise, CD166, along with a number of markers used for the identification of CCSCs, appears to be involved in cell-cell contacts [61]. Since no exhaustive information about functionally important markers are available, enhanced engraftment ability of putative CCSCs has also been supposed to be a mere result of increased expression of cell adhesion molecules on these cells [62-64].

There is scarce evidence for CD133 involvement in iron metabolism and mobility of colorectal cancer cells $[43,44]$; on the contrary, silencing experiments have shown that CD44 could have a more prominent role in tumorigenicity of colorectal cancer cells [33]. CD44 is known to be involved in many cellular activities such as survival, differentiation, and migration. Different CD44 splicing variants have also been described; some of these variants, e.g., CD44v6 expressed by several colorectal carcinomas, have been shown to be involved in c-Met activation in different cancers, allowing for maintenance of a stem cell state $[49,65,66]$.

Cancer stem cell survival may benefit from the activity of enzyme ALDH-1, which is known to mark CCSCs and to track overpopulation during colorectal tumorigenesis [37]. ALDH-1 protects cells from oxidative injury [67-69]. Moreover, by converting retinol to retinoic acid, ALDH-1 may play a role in enhancing self-renewal properties [70].

The most relevant functional activity in CCSCs is likely to be recognized in the Wnt signaling pathway. Its deregulation is known to strongly affect transition from normal colon mucosa to adenoma, whereas its activation in established cancers is pivotal to the expression of a stem cell-like phenotype [20]. Many players of the Wnt pathway are known and frequently found mutated in colorectal cancer; among these are the tumor suppressor APC and $\beta$-catenin [71,72]. With regard to the latter, the PI3K signaling pathway has also been demonstrated to be involved in $\beta$-catenin activation in colon progenitors, during progression from chronic ulcerative colitis to colitis-associated cancer [56].

\section{Targeting Colorectal Cancer Stem Cells}

Different markers have been described useful to isolate and target different CCSC populations, but actually we don't know whose of the isolated CCSC populations are responsible for cancer progression and recurrence. Anyway, eradication of colorectal cancer and its sequelae (recurrence and metastatization) may theoretically be attained by targeting specific CCSCs, provided availability of reliable markers. Some of the strategies being investigated by researchers in this field to selectively target and kill CCSCs are summarized in Table $2[45,33,35,73-83]$. Selective killing of CCSCs is indeed deemed

\begin{tabular}{|l|l|l|}
\hline Strategies for CCSCs eradication & Effects observed & References \\
\hline CD44 silencing & Apoptosis induction and tumor growth suppression & [33,35] \\
\hline Inhibition of IL-4 signalling & Sensitization to chemotherapy & [45] \\
\hline Up-regulation of BMP4 & Induction of differentiation & [73] \\
\hline Notch signaling impairment & Decreased tumor growth, reduction in CCSCs frequency, and sensitization to irinotecan & [74] \\
\hline Hedgehog signaling impairment & Proliferation impairment and apoptosis induction & [76] \\
\hline PI3K signaling impairment & Inhibition of proliferation and apoptosis induction & [76] \\
\hline Curcumin assumption & Growth inhibition, improvement of chemotherapy effects \\
\hline Sulforaphane assumption & Tumor growth impairment & [77,78] \\
\hline Epigallocatechin-3-gallate assumption & Impairment of CCSCs self-renewal \\
\hline Quercetin assumption & Inhibition of colon cancer cell proliferation \\
\hline Treatment with N-BP & Susceptibility to yס lymphocyte clearance \\
\hline
\end{tabular}

Table 2: Strategies being investigated to target colorectal cancer stem cells. 
necessary owing to the fact that conventional therapies are capable to shrink only the more differentiated bulk of the tumor, promoting selection of resistant CCSCs at the same time [84]. Indeed, CCSCs have been demonstrated to be resistant to treatment with 5-fluoracil (5-FU) and oxaliplatin $[45,85]$, which indeed yield enrichment of the CD133+/ CD44+ CCSC-like fraction [84].

Ideally, the best therapeutic approach should be capable to target all the different subsets of stem cell-like colon cancer cells within the same tumor, in order to inhibit all aspects of tumor progression (i.e., growth of the primary tumor, metastatization, cancer recurrence). Depending on their role, colorectal cancer stem cell markers should be used accordingly. For instance, functionally irrelevant markers should be exploited to vehicle drugs and toxic compounds into cancerous cells. This strategy has been explored in glioblastoma by targeting CD133 [86]. At the same time, functionally relevant markers should be antagonized by devising an appropriate therapeutic strategy. Currently, available technology permits development of specific monoclonal antibodies and gene expression or silencing techniques. However, a number of these approaches still remain experimental. Notwithstanding, promising results are being reported worldwide from investigators in the field. Monoclonal antibodies have long been used in cancer therapy. In the case of acute myeloid leukemia, antibodies directed towards CD44 have been shown to rescue the differentiation process in leukemic blasts [87]. Antibody-mediated inhibition of IL-4, a cytokine involved in apoptosis resistance in colorectal cancer cells, has been reported to sensitize colorectal cancer cells to 5-FU and oxaliplatin [45]. Restoration of differentiation in colorectal cancer cells has been obtained by induced expression of BMP4 protein, resulting in complete and long lasting regression of colon xenografts [73]. Hedgehog signaling has been found to be elevated in CD133+CCSCs with respect to the negative counterpart [74]; accordingly, knocking down the Hedgehog pathway in vitro and in vivo has been shown to result in reduced proliferation and increased apoptosis of colorectal cancer cells [74]. Interference with the Notch signaling pathway, which has been demonstrated to be essential for the maintenance of a stem cell-like state in colorectal cancer, has been associated with a decreased tumor growth and reduced frequencies of CD326+/CD166+/CD44+ stem cell-like colorectal cancer cells in colorectal cancer xenografts [75].

As previously discussed, the PI3K signaling pathway has been demonstrated to be involved in $\beta$-catenin activation in colon progenitors during tumorigenesis [56]. Thus, members of the PI3K cascade have been proposed as potential therapeutic targets for colorectal cancer stem cell-directed therapies [76].

Further innovative approaches to cancer eradication through selective killing of cancer-initiating cells are based on recruitment of immune system cells [88]. Cancer cells are known to down-regulate MHC molecules thus impairing the efficacy of immunotherapy. On the contrary, $\gamma \delta$ lymphocytes can exert their function in a MHCunrestricted fashion and be used in cancer immunotherapy more successfully. Indeed, $\gamma \delta$ lymphocytes have been isolated within tumor infiltrating lymphocytes in different cancer histotypes and their function appears to be critical for regulation of immune responses toward cancer cells $[89,90]$.

Ineffective delivery of therapeutic molecules to tumor cells may negatively affect treatment strategies. One of the more promising tools to overcome this hurdle is the use of a new generation of nanoparticles, consisting of a hydrophilic bilayer capable to encapsulate hydrophobic drugs and other therapeutic compounds. The external corona can be specifically customized by attachment of targeting antibodies, rendering these nanoparticles able to specifically deliver therapeutic molecules into cancer stem cells [91]. These nanoparticles could be functionalized to be directed to CCSCs by the use of antibodies recognizing known CCSC markers as CD133 and enclosing in the hydrophobic core drugs or small RNAs directed to silence molecules fundamental for CCSC survival, as CD44, to selectively kill these cells.

An innovative interesting attention has been recently paid to the involvement of dietary components in the cancer stem cell self-renewal [92]. In particular it has been reported the chemoprotective effects in the prevention and in the inhibition of growth of colon cancer of sulforaphane present in broccoli and broccoli sprouts [80,81]. In breast cancer cell line models it has been demonstrated that sulforaphane is able to target breast cancer stem cells thus decreasing the number of ALDH1 positive breast cancer stem cells and suppressing mammosphere production in vitro and in vivo tumor growth in mouse models [93]. Upon sulforaphane effects observed in breast cancer cell lines there is also the suppression of the Wnt- $\beta$-catenin self-renewal pathway, a pathway of fundamental importance also for CCSC maintenance and renewal [94]. A great impact in colon cancer prevention has been associated also to the consumption of curcumin, a dietary polyphenol present in the Indian spice turmeric, which is produced from rhizome of the plant Curcuma longa. Curcumin has been reported to be able to suppress Wnt- $\beta$-catenin pathway in the colon cancer cell line HCT-116 [95]. More recent studies, performed in different colon cancer cell line models, revealed that a curcumin analogue: GO-Y030, was effective in CCSC targeting increasing apoptosis and avoiding tumor growth in the mouse [96]. Moreover curcumin enhances the effects of 5-FU and oxaliplatin in mediating growth inhibition of colon cancer cells by modulating EGFR and IGFR [79]. Curcumin alone or in combination with the conventional colon cancer chemotherapeutic approach could be an effective therapeutic strategy to prevent the emergence of chemoresistant colon cancer cells by eliminating CCSCs [78].

Also the epigallocatechin-3-gallate contained in green teas has been demonstrated to be involved in CCSC self-renewal by the regulation of Akt activity both in colon cancer cell lines and in in vivo colon cancer mouse models [82]. Also an ubiquitous polyphenol known as quercetin has been demonstrated to play a role in the inhibition of Wnt- $\beta$ catenin signaling in SW480 colon cancer cell line in which it was able to impair cell proliferation by the suppression of cyclin D1 [83]. Even if to date little is known about the dietary effects on CCSC survival and targeting, the studies reported set the scene for more detailed analysis to demonstrate how combination of dietary intervention, directed against CCSCs, and conventional chemotherapy would have the potential to eliminate CCSCs, overcome tumor resistance, reduce recurrence, and eventually improve patient survival.

\section{Conclusions}

Currently no CCSC directed therapies are available for colon cancer patients. In fact, two chemotherapeutic protocols are used as first line treatment of metastatic colon cancer, namely 5-fluorouracil plus leucovorin and oxaliplatin or 5-fluorouracil in combination with leucovorin and irinotecan, respectively [97]. Neoadjuvant chemotherapy is being used in combination with anti-angiogenic drugs and epidermal growth factor inhibitors in order to increase disease-free survival and to improve overall survival $[98,99]$. However, conventional chemotherapy is limited by the inability of ridding the 
CCSCs, which are known to be often resistant to therapies. Thus, only a comprehensive knowledge of the molecular mechanisms regulating CCSC maintenance and renewal may lead to development of curative therapies. The above described approaches to targeting CCSCs are interesting and potentially useful in the development of CCSC-directed therapy but no definitive proofs have been reported for the effective possibility to use such approaches at a clinic level and their curative potential is still only at an experimental level.

In conclusion the quest for novel, definitive integrated therapeutic approaches in colorectal cancer, based on the central role of CCSCs, is ongoing worldwide and is expected to hopefully lead to breakthrough discoveries in the near future.

\section{References}

1. Vogelstein B, Fearon ER, Hamilton SR, Kern SE, Preisinger AC, et al. (1988) Genetic alterations during colorectal-tumor development. N Engl J Med 319: 525-532.

2. Markowitz SD, Bertagnolli MM (2009) Molecular Basis of Colorectal Cancer: Molecular basis of colorectal cancer. N Engl J Med 361: 2449-2460.

3. Fearon ER, Vogelstein B (1990) A genetic model for colorectal tumorigenesis. Cell 61: 759-767.

4. Nowell PC (1976) The clonal evolution of tumor cell populations. Science 194: 23-28.

5. Bonnet D, Dick JE (1997) Human acute myeloid leukemia is organized as a hierarchy that originates from a primitive hematopoietic cell. Nat Med 3: 730737 .

6. Dalerba P, Dylla SJ, Park IK, Liu R, Wang X, et al. (2007) Phenotypic characterization of human colorectal cancer stem cells. Proc Natl Acad Sci U S A 104: 10158-10163.

7. Ricci-Vitiani L, Lombardi DG, Pilozzi E, Biffoni M, Todaro M, et al. (2007) Identification and expansion of human colon-cancer-initiating cells. Nature 445: $111-115$.

8. O'Brien CA, Pollett A, Gallinger S, Dick JE (2007) A human colon cancer cell capable of initiating tumour growth in immunodeficient mice. Nature 445: 106110.

9. Ailles LE,Weissman IL (2007) Cancer stem cells in solid tumors. Curr Opin Biotechnol 18: 460-466.

10. Barker N, Ridgway RA, van Es JH, van de Wetering M, Begthel $H$, et al. (2009) Crypt stem cells as the cells-of-origin of intestinal cancer. Nature 457: 608-611.

11. Ricci-Vitiani L, Fabrizi E, Palio E, De Maria R (2009) Colon cancer stem cells. J Mol Med 87: 1097-1104.

12. Medema JP, Vermeulen $L$ (2011) Microenvironmental regulation of stem cells in intestinal homeostasis and cancer. Nature 474: 318-326.

13. Fevr T, Robine S, Louvard D, Huelsken J (2007) Wnt/beta-catenin is essential for intestinal homeostasis and maintenance of intestinal stem cells. Mol Cell Biol 27: 7551-7559.

14. Kosinski C, Li VS, Chan AS, Zhang J, Ho C, et al. (2007) Gene expression patterns of human colon tops and basal crypts and BMP antagonists as intestinal stem cell niche factors. Proc Natl Acad Sci U S A 104: 15418-15423.

15. Crosnier C, Stamataki D, Lewis J (2006) Organizing cell renewal in the intestine: stem cells, signals and combinatorial control. Nat Rev Genet 7: 349-359.

16. van Es JH, Clevers $\mathrm{H}$ (2005) Notch and Wnt inhibitors as potential new drugs for intestinal neoplastic disease. Trends Mol Med 11: 496-502.

17. Batlle E, Henderson JT, Beghtel H, van den Born MM, Sancho E, et al. (2002) Beta-catenin and TCF mediate cell positioning in the intestinal epithelium by controlling the expression of EphB/ephrinB. Cell 111: 251-263.

18. Rizvi AZ, Wong MH (2005) Epithelial stem cells and their niche: there's no place like home. Stem Cells 23: 150-165.

19. Shaker A, Rubin DC (2010) Intestinal stem cells and epithelial-mesenchymal interactions in the crypt and stem cell niche. Transl Res 156: 180-187.
20. Vermeulen L, De Sousa EMF, van der Heijden M, Cameron K, de Jong JH, et al. (2010) Wnt activity defines colon cancer stem cells and is regulated by the microenvironment. Nat Cell Biol 12: 468-476.

21. Lopez-Garcia C, Klein AM, Simons BD, Winton DJ (2010) Intestinal stem cell replacement follows a pattern of neutral drift. Science 330: 822-825.

22. Tian H, Biehs B, Warming S, Leong KG, Rangell L, et al. (2011) A reserve stem cell population in small intestine renders Lgr5-positive cells dispensable. Nature 478: 255-259.

23. Potten CS, Gandara R, Mahida YR, Loeffler M, Wright NA (2009) The stem cells of small intestinal crypts: where are they? Cell Prolif 42: 731-750.

24. Barker N, van Es JH, Kuipers J, Kujala P, van den Born $M$, et al. (2007) Identification of stem cells in small intestine and colon by marker gene Lgr5. Nature 449: 1003-1007.

25. Simons BD, Clevers H (2011) Stem cell self-renewal in intestinal crypt. Exp Cell Res 317: 2719-2724.

26. Jung $P$, Sato T, Merlos-Suarez A, Barriga FM, Iglesias M, et al. (2011) Isolation and in vitro expansion of human colonic stem cells. Nat Med 17: 1225-1227.

27. Holmberg J, Genander M, Halford MM, Anneren C, Sondell M, et al. (2006) EphB receptors coordinate migration and proliferation in the intestinal stem cell niche. Cell 125: 1151-1163.

28. Okabe M, Sawamoto K, Imai T, Sakakibara S, Yoshikawa S, et al. (1997) Intrinsic and extrinsic determinants regulating cell fate decision in developing nervous system. Dev Neurosci 19: 9-16.

29. Nishimura S, Wakabayashi N, Toyoda K, Kashima K, Mitsufuji S (2003) Expression of Musashi-1 in human normal colon crypt cells: a possible stem cell marker of human colon epithelium. Dig Dis Sci 48: 1523-1529.

30. Fujimoto K, Beauchamp, RD, Whitehead RH (2002) Identification and isolation of candidate human colonic clonogenic cells based on cell surface integrin expression. Gastroenterology 123: 1941-1948.

31. May R, Riehl TE, Hunt C, Sureban SM, Anant S, et al. (2008) Identification of a novel putative gastrointestinal stem cell and adenoma stem cel marker, doublecortin and CaM kinase-like-1, following radiation injury and in adenomatous polyposis coli/multiple intestinal neoplasia mice. Stem Cells 26 : 630-637.

32. Levin TG, Powell AE, Davies PS, Silk AD, Dismuke AD, et al. (2010) Characterization of the intestinal cancer stem cell marker CD166 in the human and mouse gastrointestinal tract. Gastroenterology 139: 2072-2082.

33. Du L, Wang H, He L, Zhang J, Ni B, et al (2008) CD44 is of functional importance for colorectal cancer stem cells. Clin Cancer Res 14: 241-246.

34. Gosens MJ, van Kempen LC, van de Velde CJ, van Krieken JH, Nagtegaal ID (2007) Loss of membranous Ep-CAM in budding colorectal carcinoma cells Mod Pathol 20: 221-232.

35. Subramaniam V, Vincent IR, Gilakjan M, Jothy S (2007) Suppression of human colon cancer tumors in nude mice by siRNA CD44 gene therapy. Exp Mo Pathol 83: 332-340.

36. Todaro M, Francipane MG, Medema JP, Stassi G (2010) Colon cancer stem cells: promise of targeted therapy. Gastroenterology 138: 2151-2162.

37. Huang EH, Hynes MJ, Zhang T, Ginestier C, Dontu G, et al. (2009) Aldehyde dehydrogenase 1 is a marker for normal and malignant human colonic stem cells (SC) and tracks SC overpopulation during colon tumorigenesis. Cancer Res 69: 3382-3389.

38. Pang R, Law WL, Chu AC, Poon JT, Lam CS, et al. (2010) A subpopulation of CD26+ cancer stem cells with metastatic capacity in human colorectal cancer. Cell Stem Cell 6: 603-615.

39. Merlos-Suarez A, Batlle E (2008) Eph-ephrin signalling in adult tissues and cancer. Curr Opin Cell Biol 20: 194-200.

40. Lugli A, lezzi G, Hostettler I, Muraro MG, Mele V, et al. (2010) Prognostic impact of the expression of putative cancer stem cell markers CD133, CD166, CD44s, EpCAM, and ALDH1 in colorectal cancer. Br J Cancer 103: 382-390.

41. Vermeulen L, Todaro M, de Sousa Mello F, Sprick MR, Kemper K, et al (2008) Single-cell cloning of colon cancer stem cells reveals a multi-lineage differentiation capacity. Proc Natl Acad Sci U S A 105: 13427-13432. 
42. Choi D, Lee HW, Hur KY, Kim JJ, Park GS, et al. (2009) Cancer stem cell markers CD133 and CD24 correlate with invasiveness and differentiation in colorectal adenocarcinoma. World J Gastroenterol 15: 2258-2264.

43. Bourseau-Guilmain E, Griveau A, Benoit JP, Garcion E (2011) The Importance of the stem cell marker prominin-1/CD133 in the uptake of transferrin and in iron metabolism in human colon cancer Caco-2 cells. PLoS One 6: e25515.

44. Elsaba TM, Martinez-Pomares L, Robins AR, Crook S, Seth R, et al. ( 2010) The stem cell marker CD133 associates with enhanced colony formation and cell motility in colorectal cancer. PLoS One 5: e10714.

45. Todaro M, Alea MP, Di Stefano AB, Cammareri P, Vermeulen L, et al. (2007) Colon cancer stem cells dictate tumor growth and resist cell death by production of interleukin-4. Cell Stem Cell 1: 389-402.

46. Shmelkov SV, Butler JM, Hooper AT, Hormigo A, Kushner J, et al. (2008) CD133 expression is not restricted to stem cells, and both CD133+ and CD133metastatic colon cancer cells initiate tumors. J Clin Invest 118: 2111-2120.

47. Horst D, Scheel SK, Liebmann S, Neumann J, Maatz S, et al. (2009) The cance stem cell marker CD133 has high prognostic impact but unknown functional relevance for the metastasis of human colon cancer. J Pathol 219: 427-434.

48. Munz M, Baeuerle PA, Gires O (2009) The emerging role of EpCAM in cancer and stem cell signaling. Cancer Res 69: 5627-5639.

49. Orian-Rousseau V, Chen L, Sleeman JP, Herrlich P, Ponta H (2002) CD44 is required for two consecutive steps in HGF/c-Met signaling. Genes Dev 16: 3074-3086.

50. Galizia G, Gemei M, Del Vecchio L, Zamboli A, Di Noto R, et al. (2012) Combined CD133/CD44 expression as a prognostic indicator of disease-free survival in patients with colorectal cancer. Arch Surg 147: 18-24

51. Chu P, Clanton DJ, Snipas TS, Lee J, Mitchell E, et al. (2009) Characterization of a subpopulation of colon cancer cells with stem cell-like properties. Int J Cancer 124: 1312-1321.

52. Haraguchi N, Ohkuma M, Sakashita H, Matsuzaki S, Tanaka F, et al. (2008) CD133+CD44+ population efficiently enriches colon cancer initiating cells. Ann Surg Oncol 15: 2927-2933

53. Huang X, Sheng Y, Guan M (2012) Co-expression of stem cell genes CD133 and CD44 in colorectal cancers with early liver metastasis. Surg Oncol 21 : 103-107.

54. Dieter SM, Ball CR, Hoffmann CM, Nowrouzi A, Herbst F, et al. (2011) Distinct types of tumor-initiating cells form human colon cancer tumors and metastases. Cell Stem Cell 9: 357-365.

55. Van Der Flier LG, Sabates-Bellver J, Oving I, HaegebarthA, De Palo M, et al (2007)The intestinal Wnt/TCF signature. Gastroenterology 132: 628-632.

56. Lee G, Goretsky T, Managlia E, Dirisina R, Singh AP, et al. (2010) Phosphoinositide 3-kinase signaling mediates beta-catenin activation in intestinal epithelial stem and progenitor cells in colitis. Gastroenterology 139: 869-881.

57. Al-Hajj M, Wicha MS, Benito-Hernandez A, Morrison SJ, Clarke MF (2003) Prospective identification of tumorigenic breast cancer cells. Proc Natl Acad Sci U S A 100: 3983-3988.

58. Li C, Heidt DG, Dalerba P, Burant CF, Zhang L, et al. (2007) Identification of pancreatic cancer stem cells. Cancer Res 67: 1030-1037.

59. Elliott BE, Ekblom P, Pross H, Niemann A, Rubin K (1994) Anti-beta 1 integrin IgG inhibits pulmonary macrometastasis and the size of micrometastases from a murine mammary carcinoma. Cell Adhes Commun 1: 319-332.

60. Fujita S, Watanabe M, Kubota T, Teramoto T, Kitajima M (1995) Alteration of expression in integrin beta 1-subunit correlates with invasion and metastasis in colorectal cancer. Cancer Lett 91: 145-149.

61. Tachezy M, Zander H, Gebauer F, Marx A, Kaifi JT, et al. (2012) Activated leukocyte cell adhesion molecule (CD166)-Its prognostic power for colorectal cancer patients. J Surg Res.

62. Tomita K, van Bokhoven A, Jansen CF, Bussemakers MJ, Schalken JA (2000) Coordinate recruitment of E-cadherin and ALCAM to cell-cell contacts by alphacatenin. Biochem Biophys Res Commun 267: 870-874.

63. Zimmerman AW, Nelissen JM, van Emst-de Vries SE, Willems PH, de Lange F, et al. (2004) Cytoskeletal restraints regulate homotypic ALCAM-mediated adhesion through PKCalpha independently of Rho-like GTPases. J Cell Sci 117: $2841-2852$

64. Kemper K, Grandela C, Medema JP (2011) Molecular identification and targeting of colorectal cancer stem cells. Oncotarget 1: 387-395.

65. Baba T, Convery PA, Matsumura N, Whitaker RS, Kondoh E, et al. (2009) Epigenetic regulation of CD133 and tumorigenicity of CD133+ ovarian cancer cells. Oncogene 28: 209-218.

66. Yamada Y, Itano N, Narimatsu H, Kudo T, Hirohashi S, et al. (2003) CD44 variant exon 6 expressions in colon cancer assessed by quantitative analysis using real time reverse transcriptase-polymerase chain reaction. Oncol Rep 10: $1919-1924$

67. Gordon MY, Goldman JM, Gordon-Smith EC (1985) 4-Hydroperoxycyclophosphamide inhibits proliferation by human granulocyte-macrophage colony-forming cells (GM-CFC) but spares more primitive progenitor cells. Leuk Res 9 : 1017-1021.

68. Sahovic EA, Colvin M, Hilton J, Ogawa M (1988) Role for aldehyde dehydrogenase in survival of progenitors for murine blast cell colonies after treatment with 4-hydroperoxycyclophosphamide in vitro. Cancer Res 48: 1223 1226.

69. Sladek NE, Kollander R, Sreerama L, Kiang DT (2002) Cellular levels of aldehyde dehydrogenases (ALDH1A1 and ALDH3A1) as predictors of therapeutic responses to cyclophosphamide-based chemotherapy of breast cancer: a retrospective study. Rational individualization of oxazaphosphorinebased cancer chemotherapeutic regimens. Cancer Chemother Pharmacol 49: 309-321.

70. Purton LE, Bernstein ID, Collins SJ (2000) All-trans retinoic acid enhances the long-term repopulating activity of cultured hematopoietic stem cells. Blood 95 470-477.

71. van de Wetering M, Sancho E, Verweij C, de Lau W, Oving I, et al. (2002) The beta-catenin/TCF-4 complex imposes a crypt progenitor phenotype on colorectal cancer cells. Cell 111: 241-250.

72. Humphries A, Wright NA (2008) Colonic crypt organization and tumorigenesis. Nat Rev Cancer 8: 415-424.

73. Lombardo Y, Scopelliti A, Cammareri P, Todaro M, lovino F, et al. (2011) Bone morphogenetic protein 4 induces differentiation of colorectal cancer stem cells and increases their response to chemotherapy in mice. Gastroenterology 140: 297-309.

74. Varnat F, Duquet A, Malerba M, Zbinden M, Mas C, et al. (2009) Human colon cancer epithelial cells harbour active HEDGEHOG-GLI signalling that is essential for tumour growth, recurrence, metastasis and stem cell survival and expansion. EMBO Mol Med 1: 338-351.

75. Sikandar SS, Pate KT, Anderson S, Dizon D, Edwards RA, et al. (2010) NOTCH signaling is required for formation and self-renewal of tumor-initiating cells and for repression of secretory cell differentiation in colon cancer. Cancer Res 70 : $1469-1478$.

76. Zhang J, Roberts TM, Shivdasani RA (2011) Targeting PI3K signaling as a therapeutic approach for colorectal cancer. Gastroenterology 141: 50-61.

77. Sharma RA, Euden SA, Platton SL, Cooke DN, Shafayat A, et al. (2004) Phase I clinical trial of oral curcumin: biomarkers of systemic activity and compliance. Clin Cancer Res 10: 6847-6854.

78. Yu Y, Kanwar SS, Patel BB, Nautiyal J, Sarkar FH, et al. (2009) Elimination of colon cancer stem-like cells by the combination of curcumin and FOLFOX. Transl Oncol 2: 321-328

79. Patel BB, Sengupta R, Qazi S, Vachhani H, Yu Y, et al. (2008) Curcumin enhances the effects of 5 -fluorouracil and oxaliplatin in mediating growth inhibition of colon cancer cells by modulating EGFR and IGF-1R. Int J Cancer 122: $267-273$

80. Zhang Y, Talalay P, Cho CG, Posner GH (1992) A major inducer of anticarcinogenic protective enzymes from broccoli: isolation and elucidation of structure. Proc Natl Acad Sci U S A 89: 2399-2403.

81. Fahey JW, Zhang Y, Talalay P (1997) Broccoli sprouts: an exceptionally rich source of inducers of enzymes that protect against chemical carcinogens. Proc Natl Acad Sci U S A 94: 10367-10372.

82. Bose M, Hao X, Ju J, Husain A, Park, S, et al. (2007) Inhibition of tumorigenesis 
Citation: Galizia G, Gemei M, Pinto M, Zamboli A, Mabilia A, et al. (2012) Different Biomarkers Address Different Colorectal Cancer Stem Cell Populations: Who's the Killer? J Mol Biomarkers Diagn S8:004. doi:10.4172/2155-9929.S8-004

in ApcMin/+ mice by a combination of (-)-epigallocatechin-3-gallate and fish oil. J Agric Food Chem 55: 7695-7700.

83. Shan BE, Wang MX, Li RQ (2009) Quercetin inhibit human SW480 colon cancer growth in association with inhibition of cyclin D1 and survivin expression through Wnt/beta-catenin signaling pathway. Cancer Invest 27: 604-612.

84. Dallas NA, Xia L, Fan F, Gray MJ, Gaur P, et al. (2009) Chemoresistant colorectal cancer cells, the cancer stem cell phenotype, and increased sensitivity to insulin-like growth factor-I receptor inhibition. Cancer Res 69: 1951-1957.

85. Cammareri P, Scopelliti A, Todaro M, Eterno V, Francescangeli F, et al. (2010) Aurora-a is essential for the tumorigenic capacity and chemoresistance of colorectal cancer stem cells. Cancer Res 70: 4655-4665.

86. Wang CH, Chiou SH, Chou CP, Chen YC, Huang YJ, et al. (2011) Photothermolysis of glioblastoma stem-like cells targeted by carbon nanotubes conjugated with CD133 monoclonal antibody. Nanomedicine 7: 69-79.

87. Charrad RS, Li Y, Delpech B, Balitrand N, Clay D, et al. (1999) Ligation of the CD44 adhesion molecule reverses blockage of differentiation in human acute myeloid leukemia. Nat Med 5: 669-676.

88. Galon J, Costes A, Sanchez-Cabo F, Kirilovsky A, Mlecnik B, et al. (2006) Type, density, and location of immune cells within human colorectal tumors predict clinical outcome. Science 313: 1960-1964.

89. Hao J, Wu X, Xia S, Li Z, Wen T, et al. (2010) Current progress in gammadelta T-cell biology. Cell Mol Immunol 7: 409-413.

90. Todaro M, D’Asaro M, Caccamo N, lovino F, Francipane MG, et al. (2009) Efficient killing of human colon cancer stem cells by gammadelta T lymphocytes. J Immunol 182: 7287-7296.
91. Blanco E, Hsiao A, Ruiz-Esparza GU, Landry MG, Meric-Bernstam F, et al. (2011) Molecular-targeted nanotherapies in cancer: enabling treatment specificity. Mol Oncol 5: 492-503.

92. Kawasaki BT, Hurt EM, Mistree T, Farrar WL (2008) Targeting cancer stem cells with phytochemicals. Mol Interv. 8: 174-184.

93. Li Y, Zhang T, Korkaya H, Liu S, Lee HF, et al. (2010) Sulforaphane, a dietary component of broccoli/broccoli sprouts, inhibits breast cancer stem cells. Clin Cancer Res 16: 2580-2590.

94. Li Y, Zhang T, Korkaya H, Liu HF, Lee B, et al. (2010) Sulforaphane, a dietary component of broccoli/broccoli sprouts, inhibits breast cancer stem cells. Clin Cancer Res 16: 2580-2590.

95. Jaiswal AS, Marlow BP, Gupta N, Narayan S (2002) Beta-catenin-mediated transactivation and cell-cell adhesion pathways are important in curcumin (diferuylmethane)-induced growth arrest and apoptosis in colon cancer cells. Oncogene 21: 8414-8427.

96. Lin L, Liu Y, Li H, LI PK, Fuchs J, et al. (2010) Targeting colon cancer stem cells using a new curcumin analogue, GO-Y030. Br J Cancer 105: 212-220.

97. Lenz HJ (2008) First-line combination treatment of colorectal cancer with hepatic metastases: choosing a targeted agent. Cancer Treat Rev 34 Supp 2: S3-S7.

98. Cunningham D, Humblet Y, Siena S, Khayat D, Bleiberg H, et al. (2004) Cetuximab monotherapy and cetuximab plus irinotecan in irinotecan-refractory metastatic colorectal cancer. N Engl J Med 351: 337-345.

99. Hurwitz H, Fehrenbacher L, Novotny W, Cartwright T, Hainsworth J, et al. (2004) Bevacizumab plus irinotecan, fluorouracil, and leucovorin for metastatic colorectal cancer. N Engl J Med 350: 2335-2342.
This article was originally published in a special issue, Potential Biomarkers and Therapeutic Targets in Cancer Stem Cells handled by Editor(s). Dr. Murielle Mimeault, University of Nebraska Medical Center, USA 